\title{
EMISSIONS IN LIFE CYCLE OF ELECTRIC VEHICLE
}

\author{
Laura Lachvajderováa, ${ }^{*}$, Jaroslava Kádárová1
}

\begin{abstract}
The paper deals with the life cycle of electric vehicle and future of reusing and recycling its battery. Investing in new alternative propulsion became an obligation to every automotive company because of the latest emissions limits. The life cycle is divided into three phases which describes a phase of production, phase of use and phase of recycling. Each of the phases has its own strategy and source of emissions. Research is focused on possible options how emissions can be reduced which helps to understand the importance of the problem. The main attention is paid to future options of reducing emissions in the recycling and reusing process, also an article focus on the analysis of expected battery life of an electric vehicle based on a comparison of selected models.
\end{abstract}

Keywords electromobility, alternative propulsions, emissions, recycling and reusing battery

\section{INTRODUCTION}

Electric and hybrid propulsions are currently considered as a promising future technology in the automotive industry. Electric motors seem to be more efficient than conventional petrol or diesel combustion engines because fully electrified vehicles produce no exhaust emissions. In addition, electric propulsion can help to become more independent of fossil fuels. On the other hand, electric vehicles (EVs) require more electricity to be produced, which can be achieved from several different energy sources with different environmental impacts. Electric propulsive units further require new advanced components of which result has in additional different environmental impacts compared to conventional vehicles. To understand the problem of the environmental impact of every product, it is important to examine its entire life cycle. From the extraction of raw materials to the pollution arising from its production, operation or the impact of waste generated during recycling, all these indicators are part of the life cycle of an EV. The major role of this type of propulsion plays the source of electricity and the rate of recycling and reuse that has in the overall huge environmental impact. In the following sections, the article focuses on question how real "green" is the production, use and also recycling of electric cars. It also deals with three phases which briefly explains the process of the life cycle of an EV and finally answers the question whether electromobility is really the way out of emission hell.

\section{EMISSIONS}

One of the main priorities of the European Union (EU) and also of the Slovak Republic, as a member of this institution, is the fight against climate change. Europe, as a world pioneer in this fight, is working hard to reduce greenhouse gas emissions, setting a good example for other countries and regions. The EU has issued a number of goals, whether with short-term or long-term character. The first set of regulations was introduced in 2009 following a voluntary commitment by the automotive industry to reduce the average $\mathrm{CO}_{2}$ emissions. The aim of the regulation was to reduce emissions from new cars by 2015 down to

\footnotetext{
${ }^{1}$ Technical University of Košice, Faculty of Mechanical Engineering, Institute of Management, Industrial and Digital Engineering, Park Komenského 9, 04200 Košice, Slovak republic

*corresponding author, phone: +421 949035 850, e-mail: laura.lachvajderova@tuke.sk
} 
$130 \mathrm{~g} / \mathrm{km}$ and by 2017 to $175 \mathrm{~g} / \mathrm{km}$. The second set of regulations, approved in 2014, required average $\mathrm{CO}_{2}$ emissions from new cars by 2021 down to $95 \mathrm{~g} / \mathrm{km}$. In the case of new, larger cars, the target value by 2020 was $147 \mathrm{~g} / \mathrm{km}$. In terms of time, the most recent targets for 2020 are $20 \%$ reduction in greenhouse gases compared to 1990, an increase in energy from renewable energy sources in final energy consumption to $20 \%$ and an approach to increase energy efficiency by $20 \%$. The long-term goal is known as Roadmap 2050, which aims under the auspices of the EU and the mission is to reduce greenhouse gas emissions to at least $80 \%$ by 2050 (Dornoff et al., 2018).

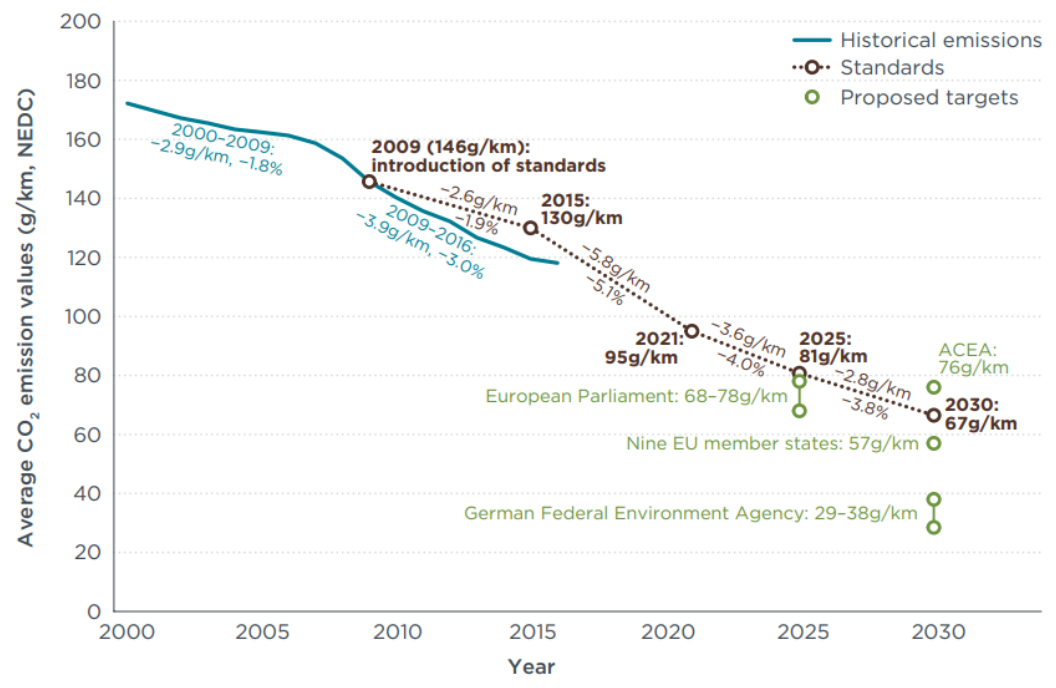

Fig. 1 Historical average $\mathrm{CO}_{2}$ emission values, standards, and proposed targets for European passenger cars. Rates in $\mathrm{g} / \mathrm{km}$ and percent refer to annual rates; source: International Council on Clean Transportation

Transport is guilty of more than $30 \%$ of all $\mathrm{EU} \mathrm{CO}_{2}$ emissions. This was also one of the reasons for setting a target for the $\mathrm{EU}$ and reducing $\mathrm{CO}_{2}$ emissions from transport by 2050 up to $60 \%$. This plays an important role in reducing greenhouse gas emissions. It is well known that emissions in transport increase collaterally with increasing mobility. Cars clearly belong to the group of the largest $\mathrm{CO}_{2}$ eminences. Its participation is up to $60.7 \%$ of total emissions in transport. The idea that one car can become the most environmentally friendly is realistic only if more people are traveling by one vehicle. However, it is statistically proven that in Europe there is one car per 1.7 passengers, which means that other transport options such as bus, appear to be a more environmentally friendly alternative. Ambitions to eliminate $\mathrm{CO}_{2}$ emissions know two real options: either by increasing the efficiency of internal combustion engines or by switching to other fuels and propulsion. 59\% of vehicles in EU has a petrol propulsion but more and more electric cars appear. Demand and sales of EVs in the EU increased by 2016 and 2017 up to 51\%. Despite the fact that the number of registered electric cars is higher every year, it still represents only a small percentage of the automotive market (Lachvajderová, 2020).

In the debate about more environmentally friendly transportation, cannot be forgotten how much greenhouse gas can car emits into the air during use, or how much the environment is polluted by the production or disposal of the car. An important fact to mention is that the production and disposal of EVs put a much greater impact on the environment compared to conventional vehicles. The life cycle of an EV can be easily divided into three phases: the production phase, the use phase and the recycling phase. Each phase focuses on the advantages and disadvantages and compares the facts with the conventional vehicle type.

\subsection{Production stage}

Compared to the production of conventional vehicles, the production of EV is significantly more energyintensive. Approximately $70 \%$ more energy is needed for Battery electric vehicle (BEV). In particular, 
these higher energy requirements may be the cause of higher emissions of greenhouse gases (Figure 2) and related air pollutants depending on the source of energy. As far as the extraction of lithium, cobalt and other metals is concerned, the production of EVs requires a number of different rare raw materials, especially for magnets used in electric motors and batteries (EEA, 2016). Many of these metals are considered critical in case the production of EVs is going to be increased, as it is not certain that these raw materials will be available in sufficient quantities (Figure 3). However, lithium, which contains lithium batteries, is not considered as an insufficient source. Worldwide shipments are plentiful, although their price has risen in recent years due to increased battery production. Lithium is the problem with the carbon footprint of EVs. The growing use of lithium-ion batteries as the main source of energy in electronic devices, including mobile phones, laptops and electric cars, has contributed to a 58\% increase in lithium production worldwide in the last decade. A recent study of car well-to-wheel (WTW) emissions in China estimates that greenhouse gas (GHG) emissions of vehicles with internal combustion engines produce about 10.5 tonnes of carbon dioxide (tCO2) per vehicle, compared with emissions of EVs of about 13 tonnes (battery production included). The $\mathrm{CO} 2$ emissions from the manufacturing of a lithium-nickel-manganesecobalt-oxide battery alone were estimated to be 3.2 tonnes. If the vehicle life is assumed to be 150,000 kilometres, WTW CO2 emissions from the manufacturing phase of an EV are higher than for fossil-fuelled cars. But for complete life cycle emissions, the study shows that EV GHG emissions are 18\% lower than fossil-fuelled cars (Qinyu et al., 2019).

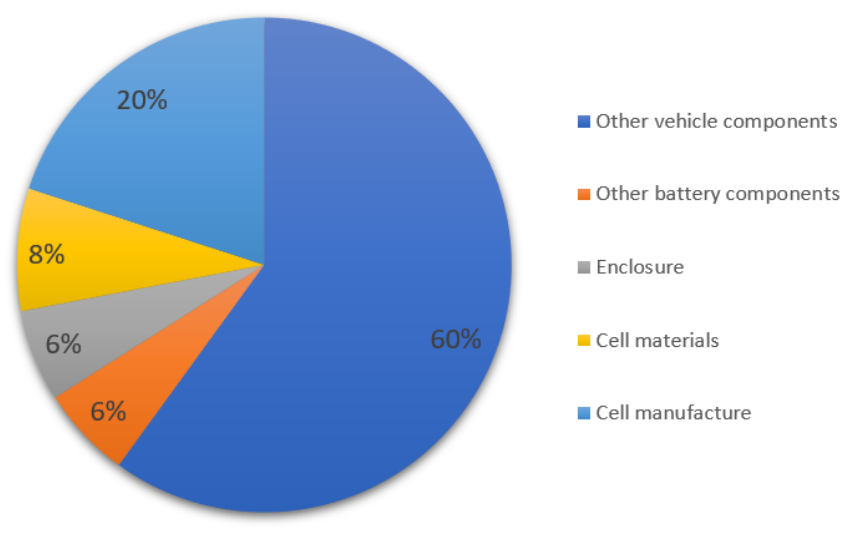

Fig. 2 Breakdown of greenhouse gas emissions from different parts of the BEV production process; source: European Environment Agency

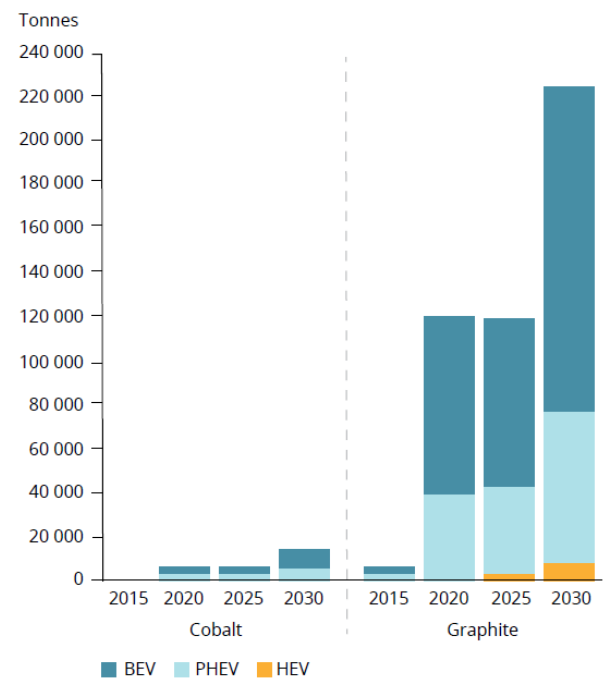

Fig. 3 Expected demand for critical raw materials in the EU by 2030 for each type of EV; source: European Environment Agency 


\subsection{Use stage}

The sources of electricity which are needed for charging batteries, such as nuclear power plants, fossil fuels in the case of a hybrid, or renewables sources, play an important role in determining the total emissions of an EV during the use phase. Any increase in the number of EVs in the future will lead to greater demand for electricity, and this will require adequate generation capacity as well as the ability of electricity networks to handle the additional amounts of electricity produced. In this case, emissions from the road transport sector will in fact be shifted to the energy sector. Even if EVs are powered by renewable energy sources, they are not zero-emission vehicles. They will still produce non excluded emissions of particulate pollutants, for example, abrasion of tire, brake and roadway. Recent research from the EEA (European Environment Agency) show that if, hypothetically, $80 \%$ of cars in 2050 were electric, $150 \mathrm{GW}$ of additional electricity generation capacity would be needed. The increase in the production of electric cars leads to a reduction in greenhouse gas $\left(\mathrm{CO}_{2}\right)$ emissions in the transport sector, but depending on the source of electricity production, additional emissions arise in the energy sector. The EEA survey shows that the additional demand for electricity is ensured by the energy mix. Future emissions of greenhouse gases $\left(\mathrm{CO}_{2}\right)$ and other air pollutants would be lower, which represents a clear net overall environmental benefit (EEA,2018). Most Life Cycle Assessments (LCA) suggest that emissions in Europe are lower than ICEV and hybrid vehicle emissions. Based on the carbon intensity of the EU electricity mix in 2015, emissions of medium-sized BEV ranged between 60 and $76 \mathrm{~g} \mathrm{CO} / \mathrm{km}$. This is $47 \%$ to $58 \%$ less than the emissions of the average medium-sized ICEV passenger car in 2015 (Figure 4).

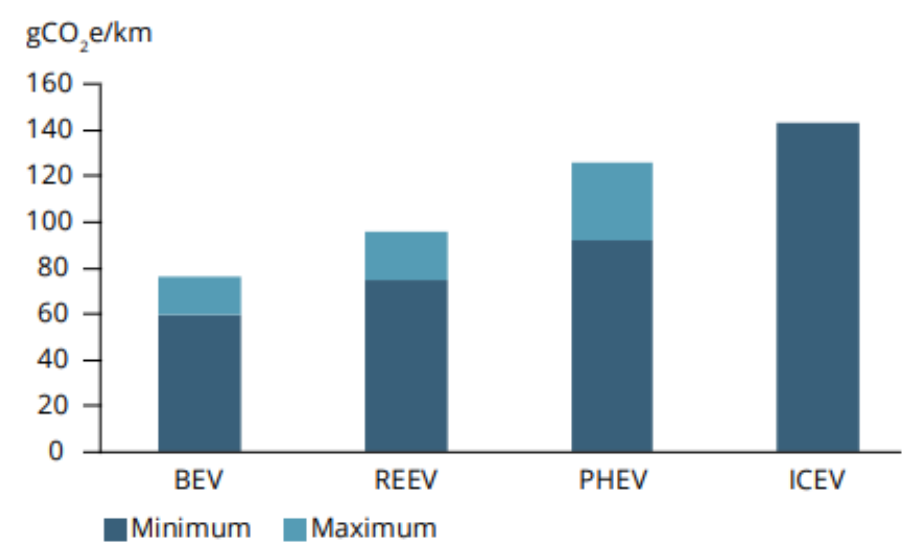

Fig. 4 Comparison of excluded greenhouse gas emissions per $1 \mathrm{~km}$ for each engine type; source: European Environment Agency

\subsection{Recycling stage}

The key processes in the recycling phase are vehicle dismantling, vehicle recycling and battery recycling. The recycling scale depends on the materials used in the production. Some materials are easy to recover and recycle (pure alloys), others are more difficult to regenerate or their ability to be reused is largely unknown. Estimated emissions at this stage, based on a study in China, are about 1.8 tonnes per ICEV and 2.4 tonnes per EV (including battery recycling). This difference is mainly caused by emissions from battery recycling, which are around 0.7 tonnes (Nordelof et al., 2014). This proves that EVs are responsible for more emissions during the recycling phase than their petrol counterparts. However, it is important to keep in mind that recycled vehicle components can be used in the production of future vehicles. The materials in the batteries are stored in thin layers and can be extracted mainly from aluminium, copper and lithium cobalt oxide $\left(\mathrm{LiCoO}_{2}\right)$. There are various methods, but currently, the most commonly used by recycling companies is the thermal decomposition method, working in a closed cycle. Li-ion, Li-polymer and NiMH cells are recycled. The cells used in this process are fed directly into the furnace without any pre-treatment by crushing, disassembly, calcination and pyrolysis. Plastics act as a reducing agent and energy source. The metals are melted and concentrated into an alloy. Examples of this procedure are the Belgian company 
Umicore, the Japanese Sony, the German Accurec, the French Citroen and many others. The efficiency of these methods is around $60 \%$, the main reason being the paradoxically frequent disregard for lithium as a recyclable component.

Currently, technologies are applied that commercially recycle batteries up to $96 \%$. For example, the German companies Duesenfeld and Redux apply hydrometallurgical methods in the processing of accumulators and batteries. The uniqueness of these companies is the use of residual stress in the cells, when they are deeply discharged directly in the plants and their energy is used to run the recycling line itself. The cells are crushed in a nitrogen atmosphere, just to prevent the reaction of water with lithium and the impending thermal event. This allows the processing of even damaged accumulators and batteries, which could not be completely relieved of residual voltage. The obtained granulate is repeatedly crushed to dust, from which individual metals are obtained by means of electrochemical processes as well as by leaching in acids.

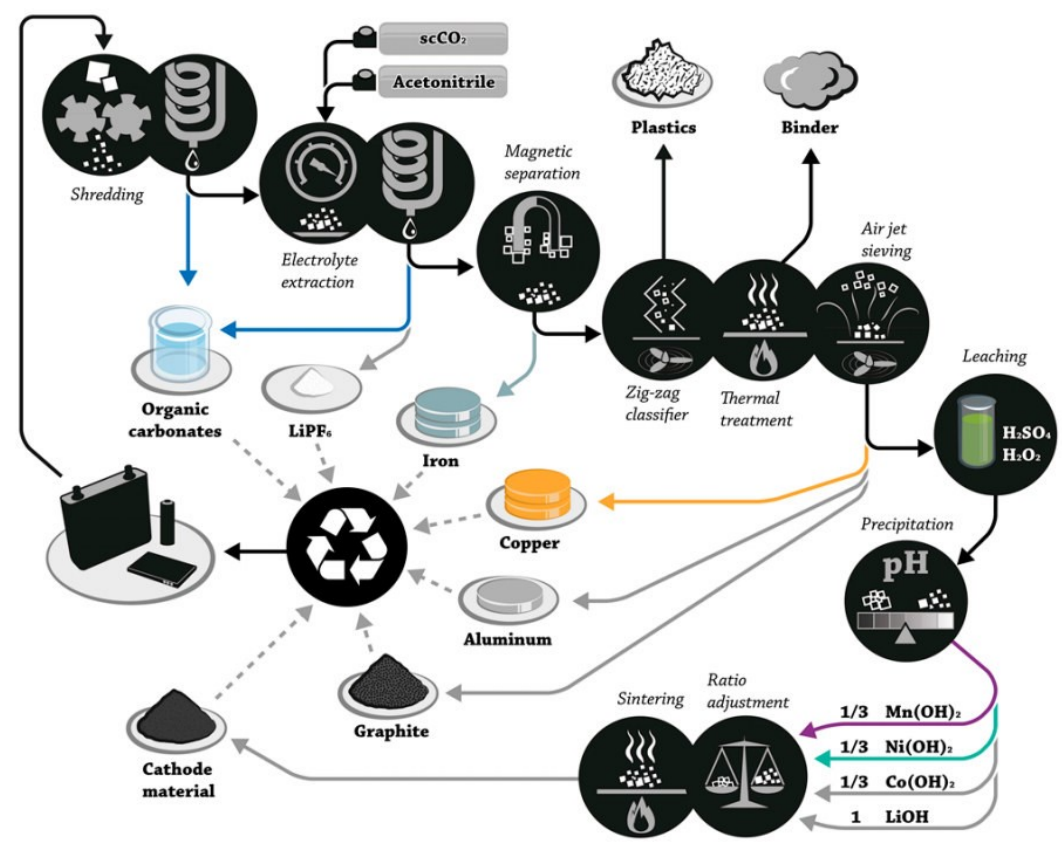

Fig. 5 Recycling scheme of various raw materials; source: Journal of powerful sources

The number of these and similar modern lines is limited by the low number of large batteries available. Of course, here and there a failure occurs on individual vehicles, or it is necessary to destroy the wreck after the accident. However, their number is far from exhausting, let alone overloading processing capacity. The plants are designed to process more than 3,000 tons of large-capacity batteries per year (Jinqui, 2008).

It is completely misleading to currently operate gigantic industrial facilities to dispose of lithium batteries and accumulators from electric vehicles. For the next 10 years, these companies would have practically nothing to do. From an operational and economic point of view, it is nonsense to build a big factory format. The ideal approach was chosen by the much-hated VW Group. A recycling centre is also being prepared for the Lithium battery production line in Salzgitter. In the first phase only as a pilot unit with an annual capacity of 1200 tons. Which, by the way, corresponds to the disposal of approximately 3,000 EVs. The car company VW has decided for the chemical process of hydrometallurgical recovery of at least $90 \%$ of basic raw materials for its own production. All car manufacturers, including battery and accumulator manufacturers, will probably take a similar step in the very near future because every battery, every accumulator is an ideal source of raw materials in almost pure form. Each car is mobile storage of materials for the production of a new vehicle, without the need for expensive purchases from primary suppliers. Every kilogram of lithium, cobalt, nickel that they will not have to buy equals an increase in profits from the sale of new models (Contestabile et al., 2001). 


\section{THE FUTURE OF REUSING AND RECYCLING BATTERY OF EV}

Battery reuse, refurbishment, refunctionalization and recycling are key constituents of the circular economy and play an important role in reducing the environmental impact of the end-of-life phase (Figure 6). Battery reuse can be direct in electric vehicles or cascading in alternative applications, e.g. for use in energy storage. Reusing batteries extends battery life and defer the need for additional processes at the end of their life. However, reuse does not eliminate the need to inspect the battery at the end of its life. Renovation and refunctionalization involve processing materials into a usable form for the same or a different function. Finally, certain materials will need to be recycled, which will help to use waste as a resource.

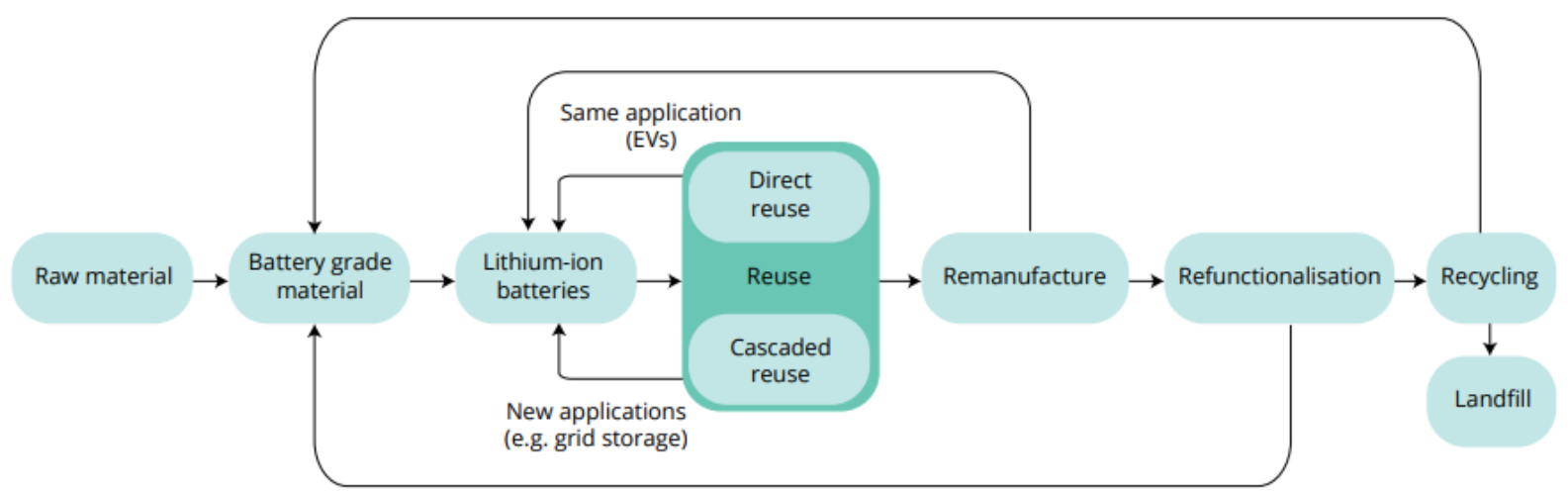

Fig. 6 Schematic representation of battery life; source: Chalmers University of Technology

Batteries usually end their life after 8 to 10 years or after 150,000 to 160,000 km when the battery capacity is below $80 \%$. Reasons for reusing batteries, respectively without recycling, such as early vehicle failure, traffic accident without battery damage or life mismatch - an older EV that received a new battery and reached its life before the capacity of the second battery is depleted (Nordelof, 2014).

Tesla EVs are doing very well in this regard. Tesla Model X of the California car rental company Tesloop has a mileage of more than 531,000 km and the range of the vehicle has decreased by $23 \%$ from $418 \mathrm{~km}$ to $322 \mathrm{~km}$. The data shows that Tesla owners will lose about $10 \%$ of the battery capacity after driving $250,000 \mathrm{~km}$. Not all car brands are doing so well, for example, Nissan Leaf batteries lose capacity faster. Leaf relies on passive air cooling of batteries, Tesla uses liquid cooling. It is the thermal management of batteries that is an important factor that causes the differences between EVs. For comparison the loss of battery capacity by model, Figure 7 shows the states of health of Tesla Model X and Nissan Leaf, where it can be seen that after 4 years of use, both models are approaching $90 \%$.

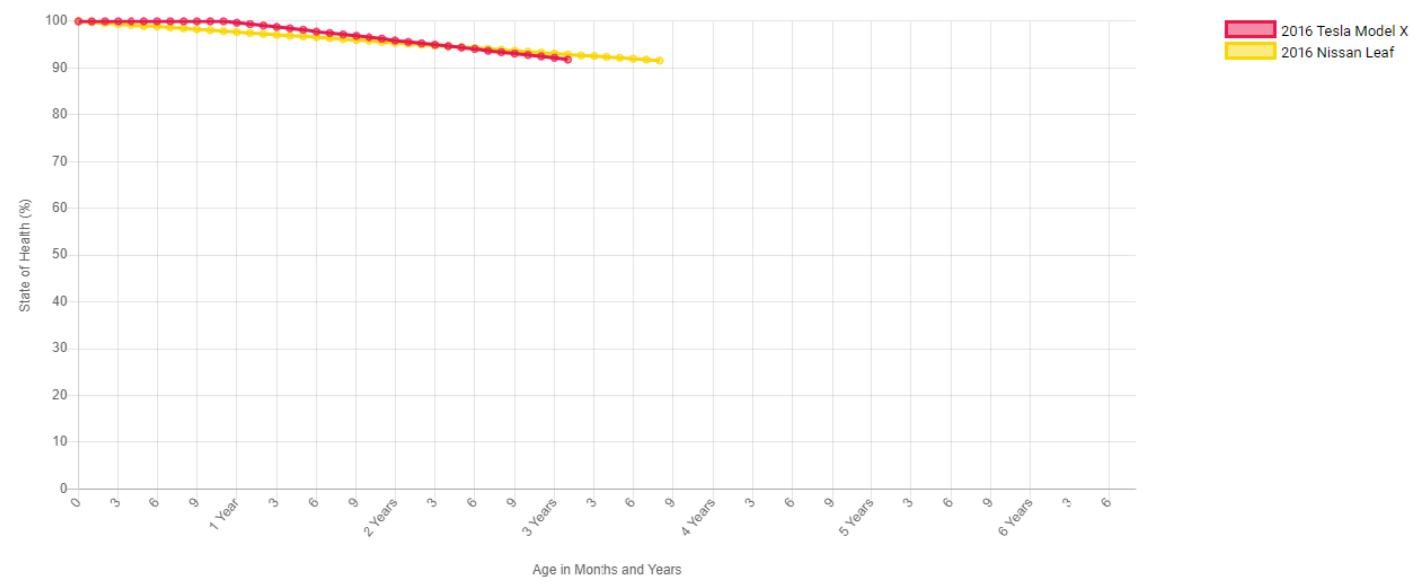

Fig. 7 Comparison of battery capacity loss according to models; source: Geotab 
Quite often it is argued that frequent repetition of charging cycles and cold have a bad effect on batteries. The results suggest that multiple charging within a week do not have a significant effect on capacity. It's similar during winter. Batteries in vehicles with an internal combustion engine often have a problem in winter. However, winter does not have to be the cause of their bad condition, only in cold weather, the bad condition will manifest itself sooner. This is also confirmed by the results in the case of EVs collected by Geotab. Capacity has dropped faster for car batteries driving in hot areas. Here it is necessary to take into account that temperature itself does not have to be the cause, only the common denominator (Geotab, 2019).

Research modelling the impact of 1,000 EVs suggests that reusing used batteries in EVs could bring a net benefit of a cumulative energy requirement of up to 200,000 MJ. This equates to 11 new batteries for EVs, which are not needed for production. Cascading use involves the use of batteries in a variety of less demanding stationary applications. This avoids the burden of manufacturing new battery packs. Reuse in this way can also have economic benefits due to the value of reselling used batteries and thus avoiding the cost of buying a new battery. However, further research into the cascading reuse of batteries for electric vehicles is needed, and in particular to understand the degradation of battery components, in order to better assess the potential for reuse and the most efficient application. Research projects in this area are just beginning and second-hand battery applications are gaining interest around the world. In general, studies have found significant savings in greenhouse gas emissions through the reuse of batteries, as electric vehicles are becoming more popular, especially when this reuse allows renewable energy to displace competitive energy from fossil fuels.

\section{CONCLUSIONS}

The reduced emissions over the lifetime of the electric vehicle are expected to outweigh the environmental impacts of the production and recycling phases. Electric vehicles can therefore significantly reduce the negative environmental impact of conventional passenger cars, of course, if the electricity is derived from environmentally friendly energy sources. If the whole life cycle is taken into account, the electric vehicle itself does not guarantee zero emissions. If the electric vehicle would derive energy from renewable energy sources, in this case, it will be the most environmentally friendly option and emissions from transport have a chance to decrease. It is important to look at the issue from all sides, respectively. There is a need to name energy issues and further studies need to focus on a more detailed study of battery recycling and reuse, which can guarantee a new positive, economic and emission aspect.

\section{Acknowledgements}

This document has been prepared in support of a grant project KEGA 009TUKE-4/2020 Transfer of Digitization into Education in the Study Program Business Management and Economics.

\section{References}

Contestabile M., Panero S., Scrosati B. 2001. A laboratory-scale lithium-ion battery recycling process. Journal of power sources. Volume 92, pp. 65-69.

Dornoff, J., Miller, J., Mock, P. and Tietge, U. 2018. Level and timing of emission targets. The European Commission regulatory proposal for post-2020 CO2 targets for cars and vans: A summary and evaluation. ICCT Briefing, January 2018, pp. 3-5. The international council on clean transportation. [online]. Available at: https://theicct.org/sites/default/files/publications/ICCT_EU-CO2-proposal_briefing_20180109.pdf [Accessed: 2020, September 30]. 
European Environment Agency (EEA). 2016. How environmentally friendly are electric vehicles? Electric vehicles in Europe, volume (20). Copenhagen, Luxembourg: Publications Office of the European Union, pp. 41-45. DOI: $10.2800 / 100230$.

European Environment Agency (EEA). 2018. Production stage. Electric vehicles from life cycle and circular economy perspectives, volume 13. Copenhagen, Luxembourg: Publications Office of the European Union, pp. 22-32. DOI: $10.2800 / 77428$.

Jinqui, X. 2008. A review of processes and technologies for the recycling of lithium-ion secondary batteries, Jurnal of power sources, volume 177, Issue 2, ISSN:0378-7753.

Lachvajderová, L. 2020. Emissions. Electromobility as part of the transition strategy to emission-free forms of transport. Košice, Slovakia: Technical University of Košice, Diploma thesis, pp. 32-37.

Nordelof, A., Tillman, A., Messagie, M. and Van Mierlo, J. 2014. Less or different environmental impact? Systems perspectives on electromobility. Göteborg, Sweden: Chalmers University of Technology, pp. 60-63. [Online]. Available at: http://www.chalmers.se/en/areas-of-advance/energy/cei/Pages/SystemsPerspectives.aspx [Accessed: 2020, September 29].

Qinyu, Q., Fuquan, Z., Zongwei, L., Xin, H., Han, H. 2019. Energy. Life cycle greenhouse gas emissions of Electric Vehicles in China: Combining the vehicle cycle and fuel cycle, volume 177. Beijing, China: Tsinghua University, pp. 222-233. [Online]. Available at: https://doi.org/10.1016/j.energy.2019.04.080 [Accessed: 2020, October 19]. 